ZOHAR BIBER

Higher Studies Israel

\title{
ATTITUDES OF ADOLESCENTS TO THE INVOLVEMENT OF THEIR PARENTS IN THE SCHOOL: THE RELATIONS BETWEEN PARENTS AND TEACHERS
}

\begin{abstract}
Biber Zohar, Attitudes of Adolescents to the Involvement of their Parents in the School: the Relations Between Parents and Teachers [Postawy młodzieży względem zaangażowania szkolnego rodziców: kontekst stosunków między rodzicami a nauczycielami]. Studia Edukacyjne nr 40, 2016, Poznań 2016, pp. 261-282. Adam Mickiewicz University Press. ISSN 1233-6688. DOI: 10.14746/ se.2016.40.15

Since the concept of the 'school' has existed, the triangle of parents, teachers, and students, in all that relates to the parental involvement in the school, has constituted a significant factor that saw 'ups and downs' over the years. Some supported the separation between the student's home and the school, while others saw the connection and cooperation between them to be essential. This article examines students' attitudes towards their parents' involvement in school. This article will present the difficulties adolescents have with their parents' authority and treatments for the era in which we live. Some research studies have found a correlation between parental involvement and its impact on children. The research study diagnoses the students' positions according to quantitative questionnaires that were built and used. After analyzing quantitative questionnaires, the research attempted to draw conclusions about the tension that exists between the theories and studies showing the benefits of parental involvement regarding the results of the quantitative questionnaires.
\end{abstract}

Key words: parental involvement, middle school, adolescence, media

\section{Introduction}

Since the concept of the 'school' has existed, the triangle of parents, teachers, and students, in all that relates to the parental involvement in the school, has constituted a significant factor that has seen 'ups and downs' over the years. Some supported the separation between the student's home 
and the school, while others saw the connection and cooperation between them to be essential. The student is found between the school and the parental home - and he too has an opinion on the mater.

In this article, I will address the attitudes and opinions of the students in all that relates to the involvement of their parents in the school. This research study will examine the attitudes of all the partners in the educational process, namely teachers, principals, parents, and students, in areas related to the parents' involvement in the school, in organizational and educational activity, and in the setting of the school policy and platform. I will present research studies that found an influence of the parents' cooperation with school activities on their children. I will examine the influences of the new media on the parents' involvement in the school, and I will examine and analyze the students' attitudes towards their parents' involvement in the school according to a quantitative questionnaire I prepared.

\section{The Involvement of the Parents in the School: Definition}

The research literature presents different models for the description of the reciprocal relations between the school and the parents. ${ }^{1}$ In the present work, I based on the research of Bauch and Golding2 for the examination of the contribution of the discourse on the new media for the increase of the parents' involvement in the school activity. This model includes the following types:

1. Bureaucratic, characterized by little involvement of parents and teachers. This is the traditional model, in which parents have a passive role while the teachers maintain their autonomous place in the classroom.

2. Teachers' professionalism, characterized by great involvement of the teachers and low involvement of the parents. In this model the teachers are perceived as experts and as knowing what is good for their students.

3. Parent empowerment, characterized by high involvement of the parents, as opposed to low involvement of the teachers. In this model, the parents can constitute a threat to the professional prestige of teachers and in

${ }^{1}$ C. Olmstead, Using technology to increase parent involvement in schools, TechTrends, 2013, 57(6), p. 28-38; A. Addi-Raccah, R. Ainhoren, School governance and teachers' attitudes to parents' involvement in schools, Teaching and Teacher Education, 2009, 25(6), p. 805-813.

2 P.A. Bauch, E.B. Goldring, Parent-teacher participation in the context of school governance, Peabody Journal of Education, 2000, 73(1), p. 15-35. 
actuality weaken them. In this model, the relations between teachers and parents are characterized by tension and the teachers' aspiration is to distance the parents as much as possible.

4. Partnership, characterized by a high level of involvement of both the teachers and the parents. This model aspires to the optimal involvement of the parents.

\section{Adolescence: From Childhood to Adulthood}

The period of adolescence is defined sociologically as the period of transition from childhood, when the person is dependent, to adulthood, when the person provides his own needs. The period of adolescence begins at the age of ten to twelve and is characterized first by physical-sexual development. In Israel, the end of adolescence is determined by the chronological age of eighteen, when the person is drafted into a term of compulsory military service.

Adolescence is characterized by changes in a number of areas: physical, emotional, family, and social. From the physical perspective, adolescence is characterized by the appearance of the indications of sexual development and concludes with the end of the physical growth, when the person has the ability to reproduce. These changes are primarily controlled by neural and hormonal factors and are influenced by genetic and environmental factors. The adolescent must adapt to these changes and must accept them as a part of him. Every adolescent responds differently, and there are fluctuations in the mood. From the cognitive perspective, in this period the thinking develops and the person achieves adult thinking. There is a transition from concrete thought to abstract thought and a transition from subjectivity to objectivity. The person has the ability to address a complex reality, the ability of phrasing, generalization, and understanding of rules, critical thinking, perception of time that enables understanding on the continuum of past, present, and future. In this stage, adolescents do not accept things as obvious; they cast doubt, conflict, and dispute the frameworks and institutions existing in society.

The transition from childhood to adolescence occurs at different ages among different youths and entails developments that vary from one youth to the next. Adolescence is the outcome of many factors combined together biological, social, cultural, economic and even political factors. Although the 
transition to the period of adolescence is a clear fact, different philosophers addressed this transition from different angles.

Childhood is also a period that is not precisely delineated in terms of the age range. Different researchers addressed childhood as beginning from approximately the age of three, after the toddler has achieved important milestones in the motor and language domains - he can walk without problems and can express himself in words. Others addressed childhood as if it begins with the age of the entry into the school, a transition that constitutes a significant change for the child and his environment. Childhood ends when adolescence commences; but this is not a certain age or set point in time and this depends, as aforementioned, on many factors. ${ }^{3}$

In contrast to childhood, which is a relatively calm period, adolescence, which lasts a number of years, is a period of many changes in many areas of the person's life. The beginning of adolescence occurs following biological (hormonal) factors, and its end is determined primarily by social and cultural factors. In this period, the youth is no longer a child but is not yet an adult. The transition to adolescence begins, as aforementioned, because of biological factors. The physical-biological transition is called puberty. The start of the biological change has been occurring at an earlier age over the years. While in the generation of the parents, the girl began menstruation around the age of thirteen-fourteen, today girls aged nine and ten can be menstruating. This is one month for every decade in the age of the appearance of the menstruation. From a social perspective, in Jewish society the transition is symbolized by the Bat Mitzvah ceremony held at the age of twelve for girls and the Bar Mitzvah ceremony at the age of thirteen for boys.

In different cultures and religions, there are other rites that symbolize the transition from childhood. From a social and academic perspective, the beginning of adolescence is marked by some children by the end of the elementary school and the transition to the middle school. Another important social change, which is gradual and not localized, is the rise of the importance of the peer group and the partial reduction of the importance of the family. While the child admires his parents, the adolescent de-values them and sees their shortcomings. This change is essential in psychological terms so as to allow for the adolescent's most important task: separation and independence.

3 S. Sohlberg, Psychology of the child and the adolescent - Introduction to developmental psychology, Jerusalem 1994. 
These changes, which note the transition from childhood to adolescence, do not always occur at the same time and are not always fully synchronized. Thus, for example, hormonal adolescence begins in girls aged nine to eleven and in boys about two years later. While girls begin monthly menstruation at the age of nine, on the average (the datum addresses American girls), this age is noted socially only at the Bat Mitzvah, when the girl reaches the age of twelve.

Although the changes reviewed previously are the most apparent, the beginning of the age of adolescence brings with it apparent changes in the youth's brain as well, primarily in the reduction of the number of synapses (pruning) in different regions of the brain. In addition, from a biological perspective there is a change in the metabolism and in the need for sleep. Other changes include changes in the cognitive abilities, quantitative and qualitative changes. Thus, for example, youth can begin to understand concepts of logic and probability, and there is an improvement in the ability of abstraction. Additional changes occur in the social understanding and in the social abilities and in the perception of morality. These changes influence the youth's relation with his parents and sometimes lead to conflicts with the parents. In parallel, the youth becomes more independent and his ability to care for himself increases.

A number of theoreticians have proposed development theories, which included childhood and adolescence. The first was Sigmund Freud, who saw the transition from childhood to adolescence to be a transition from the stage of latency to the genital stage. According to psychoanalytical development, the stages are determined according to the different regions of the body on which the erotic (libidinal) activity focuses at different ages. Freud defined the latency period, ages five to eleven, as the period in which there are no sexual drives, a situation caused as a result of the successful resolution of the Oedipal stage. This period ends with the re-awakening of the sexual drives at the beginning of adolescence. Beyond the awakening of the sexual drives, the child goes from a stage in which he focused on learning and acquiring skills to a stage in which conflicts from previous stage are opened, which on the one hand, leads to disquiet but on the other hand, enables the resolution of these conflicts. ${ }^{4}$

Erikson ${ }^{5}$ developed a developmental theory that in part is in parallel to Freud's theory. However, its perspective is social - Erikson divided the development into stages according to the relations between man and the envi-

4 S.A. Mitchell, M.G. Black, Freud and Transition, Tel Aviv 2006, p. 17-72.

${ }^{5}$ E.H. Erikson, Childhood and Society, Tel Aviv 1983. 
ronment around him. He divided the person's life, from infancy to old age, into eight stages, and in every stage he defined the successful conclusion versus the failure of the developmental stage. The stage of childhood, age five to thirteen according to Erikson, is the fourth developmental stage, and its successful conclusion leads the child to be industrious - to have the ability to work or to learn. The unsuccessful end of this stage will lead to inferiority. According to Erikson, only after the person has achieved the developmental goals of the stage of childhood can he move to the next stage of adolescence. His task in adolescence will be the construction of the identity. Abnormal development in the stage of adolescence will lead to confusion in the social roles.

Another important theoretician, who also divided human development into stages, was Jean Piaget. 6 The stages in his theory were determined according to the cognitive development. Piaget called the period of childhood the stage of concrete operations. In this stage, the child operates and acts on objects and events that are real and concrete. When the child enters adolescence, he moves to the stage of formal operations, in which the actions are formal (as opposed to concrete) - logical, methodical, symbolic, and abstract. It is interesting to note that Piaget maintained that not all people reach this stage.

Lawrence Kohlberg7 based on the developmental theory proposed by Piaget and added another dimension to it - the developmental of morality. Kohlberg saw childhood to be a stage in which children uphold the laws of morality to maintain good relations with others. In contrast, during adolescence the young person internalizes the principles of morality, uses them since he wants to do so, and can characterized the situations in which deviation from the rules of morality is necessary, according to the circumstances. Deficiencies in this field will be expressed in behavior disorders and delinquency.

Peter Bloss8, a classic theoretician of adolescence, saw adolescence to be the second separation that began at the age of toddling (0-36 months). He coined the concept of second separation and individuation.

One of the most common dilemmas in the period of adolescence is the degree of freedom that should be given to adolescents. The opinions on this are different, both among the parents and among the adolescents, and there

${ }^{6}$ J. Piaget, The Psychology of the Child (transl. Y. Sternberg), Tel Aviv 1972.

7 D. Statman, Moral Dilemmas, Hebrew University, 1991.

8 W. Meeus, Parental and peer support in adolescence, [in:] The social world of adolescents, Eds. K. Hurrelmann, U. Engle, New York 1989, p. 167-185. 
is no one right answer. This changes from family to family, from adolescent to adolescent, and frequently in the same family every adolescent requires a different degree of freedom. However, it is necessary not to forget that even if they do not admit it, adolescents want boundaries; these are logical, flexible, and negotiable boundaries, but these are boundaries.

The issue of the setting of boundaries is central in adolescence, and frequently it creates conflicts between parents and adolescents. In essence, the need to set boundaries creates a dilemma that causes confusion and tension among both parents and adolescents.

From the perspective of the parents, on the one hand, they want their adolescent to learn to be more responsible and to act more maturely. On the other hand, the parents do not always rely on the adolescent's judgment, do not always agree with the independent decisions he makes, and are not always willing to take the risks that he is willing to take. Some parents fear that giving independence to adolescents will reduce their influence.

From the perspective of the adolescents, on the one hand, they want to attempt new things and to feel they are older and thus they do not want to be told what to do (what time to return home, when to prepare homework, who to go out with, and how to dress). They think that the way to form their identity is through the rejection of their parents' identity. On the other hand, the period of adolescence is characterized by uncertainty, with many difficulties and many challenges. The adolescent aspires to attempt new experiences, especially experiences that belong to the world of adults however, these experiences lead him sometimes to situations that require mental powers and life experience that he does not yet have at his disposal. In these cases, it becomes clear that nevertheless he still needs his parents a little. ${ }^{9}$

Therefore, both parents and adolescents experience adolescence as a period of tensions, between closeness and distance, between dependence and independence, between convergence and explosion. These contradictions do not necessarily create conflicts between adolescents and their parents.

\section{New Channels of Communication between Parents and Teachers}

This section focuses on a number of issues relevant to the examination of new channels of communication between teachers and parents and their

9 E. Meizles, Relations between parents and adolescents with the transition to adolescence, Trends, 2001, 41(1-2), p. 180-194. 
implications on their involvement in the educational process of their children and students. The involvement of the parents, including the communication with the staff in the school, has influences on the student's wellbeing, cognitive development, and consequently achievements. ${ }^{10}$

A direct, personal, and quality relationship between the parents and the teaching staff is an essential condition for the optimal parental involvement in the life of the school.11 Effective communication between parents and teachers and an open channel of communication are very important and have a positive influence on the problem solving, which may improve the quality of education, sense of belonging, and success of children. The researchers further found that the parents' involvement will increase as they feel that the school trusts them and as they feel identity with the school values. In reality, in contrast, the process of parental involvement encounters difficulties. For instance, the Committee for Family Relations in Early Childhood Education and Connection to the Child's Development and the Success in the Educational System expressed frustration regarding the parents' involvement in the school because of the fact that the school turns to the parents only in the case of a conflict or a problem. The committee members' evaluation is very important to the involvement of the parents in the successes and positive messages. ${ }^{12}$

Information and communication technologies develop tremendously fast. They penetrate into every field, change our lifestyles, and become an important part of our culture and a main element in every field of existence. ${ }^{13}$ The same is true for the channels of digital communication between the school and the parents. The availability of new channels of media, for example, email, social networks (such as Facebook, WhatsApp), systems of institutional communication (as in the example of Mashov ${ }^{14}$ and Smart

10 A. Plotkin, T. Shapira, Contribution of the cooperation between the school and the parents in the construction of educational authority, Trends in the Administration of Education 2103 Conference, Book of Abstracts, 2013; S.G. Kosaretskii, D. Chernyshova, Electronic communication between the school and the home, Russian Education and Society, 2013, 55(10), p. 81-89; C. Olmstead, Using technology to increase parent involvement, p. 28-38.

11 Y. Friedman, Relations between School and Parents in Israel: Background Material for the Work, 2010; Y. Fisher, Y. Friedman, Parents and the school - Reciprocal relations and involvement, Pages, 2002, 47, p. 11-37; A. Mor, To speak with the parents even when 'everything is alright', Echo of Education, 2012, 90.

12 Z. Greenbaum, D. Fried, Family relations in the framework of early childhood education: Picture of the Situation and recommendations, Israel National Academy for Sciences 2008.

${ }^{13} \mathrm{G}$. Salomon, Technology and education in the information era, Haifa and Tel Aviv 2000.

14 Mashov is a Hebrew acronym for Immediacy, Transparency, and Supervision. The word means feedback. It is an Internet-based system of school management developed in the year 2006. As of the year 2014. it has been deployed in 549 schools and educational systems in 
School) and smartphones offer synchronous and asynchronous, interpersonal, intergroup, dynamic communication that did not exist beforehand.

Research studies show that electronic mail (email), an old digital implementation from the period of Web 1.0, is one of the most common means for communication between parents and teachers. According to teachers, the evaluation of the parents through the email facilitates with the adoption of the steps required for the assistance of students who need help..$^{15}$

Electronic mail is found to be effective in the management of the students by the teachers, in that the messages are conveyed immediately to the parents. However, the main communication between the two groups occurs around negative issues, both in terms of the scholastic achievements and in terms of the behavior in the school. However, it was found that the parents and the teachers attempted to phrase the negative information in a positive vein. ${ }^{16}$ Thompson ${ }^{17}$ in another research study found failures and fears in the use of this channel of communication: (1) erroneous interpretation of the message, (2) fears of the use of asynchronous media, (2) fear of crossing the boundaries between teachers and parents, and (4) fear of shifting the responsibility for learning from the students to the parents.

Comparison between communication through the school website and email indicated that the institutional systems for pedagogical and administrative management, such as the examples of Mashov, MNBST18, and Smart School, are another channel of communication. Through these systems it is possible to obtain a daily report about what occurs in the lessons in the school and a report on the scores and scholastic achievements. The systems enable intra-organizational communication between staff members and communication with the students and their parents. ${ }^{19}$ It should be noted that

Israel. The use of this software by the school staff, the students, and the parents contributes to the transparency of school activity through regular updates, for the improvement of the relationship between the school staff and the student and his parents and the improvement of the efficiency of the daily work in the educational staff.

15 S.G. Kosaretskii, D. Chernyshova, Electronic communication between the school and the home, Russian Education and Society, 2013, 55(10), p. 81-89; B. Thompson, Parent-teacher e-mail strategies at the elementary and secondary school, Qualitative Research Reports in Communication, 2008, 10(1), p. 17-25; B. Thompson, Characteristics of parent-teacher e-mail communication, Communication Education, 2009, 57(2), p. 201-223.

16 B. Thompson, Parent-teacher e-mail strategies, p. 17-25.

17 B. Thompson, Characteristics of parent-teacher e-mail communication, p. 201-223.

18 MNBST stands in Hebrew for Internet School Management System. It is a system open for use by all schools and is a work tool that enables the management of the school schedule and the report and follow-up after student attendance, behavior, and evaluation.

${ }^{19}$ Y. Binns, The use of the Mashov [Immediacy, Transparency, Supervision] program in the dialogue between the parents and the school: The Kafr Kaana middle school, M.A. Thesis, The Open University 2008; C. Olmstead, Using technology to increase parent involvement, p. 28-38. 
the educational system in Israel set for itself as an objective the incorporation of institutional systems as a main communication channel. The national computerized communication program that commenced in the year 2010 explicitly declared that one of the goals of the encouragement of communication between teachers, parents, and students is through information systems for pedagogical management. ${ }^{20}$

Research studies found that the pace of the adoption of the institutional systems has increased and that these systems have a main place in the management of the school and in the communication between teachers, students, and parents. For instance, Blau and Hameiri ${ }^{21}$ measured the number of entries into the Mashov system in seven secondary schools in the first three years of the system. The research findings indicate that as the teaching workers entered data into the Mashov system, the pace of entries of the parents (primarily mothers) and of the students increased and consequently the frequency of the interaction between the teachers and the parents also increased (the nature of the interaction was not examined). However, teachers (with the exception of beginning teachers) reported mental pressure and fear of criticism on the part of experienced teachers, management, and parents following the public documentation of their reports. One of the results was that in some of the cases the report was 'softened' and not fully faithful to the reality.22

Additional new channels of communication are the social networks, like Facebook, WhatsApp (used to send immediate messages, photographs, and video and sound clips), Twitter, Google Plus, and so on. Social networks are the name of environments that include a variety of online tools and means that enable the creation and preservation of relations between users 24:7. The networks are a part of the variety of Web 2.0 applications, which are characterized by creation and collaboration of contents between users with shared interest. The world on the social networks is a world of 'here and

${ }^{20}$ Ministry of Education, Adjustment of the educational system to the 21st century: Masterplan, 12th edition, http://goog.gl/6oKIJb, 2012.

${ }^{21}$ A. Blau, M. Hameiri, Smartphone in the school - Is the next generation really here? Pedagogical management of the mobile phone in the educational staff and in the families, [in:] The learning person the technological era, Eds. Y. Ashet Alkaly, A. Kaspi, N. Gary, Y. Kellman, V. Silver-Varod, Y. Yair, 2011, p. 17-24; A. Blau, M. Hameiri, A new way to realize the right to know: Increase of the involvement of students and parents in what is done in the educational institutions through an online system for pedagogical management - Mashov [Immediacy, Transparency, Supervision], 2012, http://goog.gl/BO1pxt

${ }_{22} \mathrm{M}$. Perlman, What are the reciprocal relations between the teachers' use of systems for information management and their sense of accountability? [in:] The learning person the technological era, Eds. Y. Ashet Alkaly, A. Kaspi, N. Gary, Y. Kellman, V. Silver-Varod, Y. Yair, 2014, p. 74-79. 
now', when users look, respond, and are present. ${ }^{23}$ Facebook is the largest and most known social network in the world. As its founders state, "Connect with friends and the world around you on Facebook". ${ }^{24}$ The use of the environment is free and allows the user (from the age of thirteen up) to join a group or groups of users and to communicate with the other members of the group. The users can create for themselves a personal profile and a list of people to whom it is possible to send messages and with whom it is possible to share information, pictures, and films. The research indicates that this social channel still is in its infancy as a channel of communication between teachers and parents but teachers express a willingness in principle to use it. ${ }^{25}$

Brooks and Boskilla ${ }^{26}$, who examined the incorporation of the Facebook social network as a means of communication between teachers and parents, found that most of the parents (81\%) who participated in the research study maintained that Facebook is an effective tool for the improvement of the rapid communication between them and the class teachers, in contrast to traditional means, which are not rapid and accessible immediately for performance, such as contact notebooks and telephone calls. In addition, most saw Facebook to be a way that makes it easier for them to receive daily information from the teachers in the class, both through general messages and through personal messages and personal requests. The research study further shows that the relation between the parents and the teachers changed for the better as a result of the experience of communication between them using Facebook. They maintain that the communication through Facebook contributed to the extension of the trust and cooperation between the teachers and the parents. During the school year in which the research study was performed, the relationship between the teachers and the parents was extended from the contact notebook and weekly telephone calls to daily contact, which is independent of time and place. Many parents responded via their mobile phone immediately after the message was sent. The parents felt that the communication was strengthened and led to mutual relations of trust. Another finding of their research study showed that the transfer of information and the exposure of the parents to different contents contributed greatly to the feeling of partnership. Aside from the messages brought up by the teachers about different activities held in the class, parties, pic-

${ }^{23}$ G. Kortz, D. Chen, Intentional online learning - A digital toolkit for the teacher, Center for Academic Studies, Or Yehuda 2012.

24 https://www.facebook.com/

${ }^{25}$ C. Olmstead, Using technology to increase parent involvement, p. 28-38.

26 S. Brooks, D. Boskilla, Incorporation of Facebook as a means of communication between teachers and parents: Action research, M.A. Thesis, The Center for Academic Studies 2013. 
tures, and so on, the parents brought up pictures from their everyday life at home, ideas for trips, and suggestions for joint activities.

The accelerated development of wireless technologies infrastructures contributed to the appearance of mobile means a, including smartphones that have internet access and allow a variety of actions of communication and browsing. Smartphones provide possibilities of communication in a variety of visual, text, and audiovisual representations. In addition, they increase the frequency of the use of communication applications such as email, Facebook, WhatsApp, Webtop (a Smart School application for the mobile phone), and so on.

Blau and Hameiri27 examined the use of smartphones for work with the Mashov system among teaching workers, students, and parents in 429 schools. The data were based on system data (not self-reporting). They found that the number of entries of teaching workers into the system from the smartphone influenced the number of entries of students and parents. In their opinion, the possibility of entering data from the smartphone in realtime during the lessons can reduce the load assigned to the teaching workers in the entry of continuous data into the system and in freeing their time in the recesses, stay hours, and after the work day for additional educational activity. Moreover, the use of the Mashov system creates a new culture of online interaction between the school and the students and their parents.

To conclude, the limited review of research studies presented in this section shows that the appearance of digital channels of communication and communication means such as smartphones offer a variety of communication processes that had not existed beforehand both in their visual design and in the access to them. One of the main questions addresses the degree to which the technological setting changes and may change even more so in the future the nature of the relationship between the teachers, students, and parents.

\section{The Meaning of the Changes that Occurred in the Relationship between Parents and Teachers}

Parents and teachers have an important place in the developmental and educational process of the students. Parents and teachers are partners in the

27 A. Blau, M. Hameiri, A new way to realize the right to know: Increase of the involvement of students and parents in what is done in the educational institutions through an online system for pedagogical management - Mashov [Immediacy, Transparency, Supervision], 2012, http://goog.gl/ BO1pxt 
process in which the adolescents acquire values, education, and norms of behavior. The educational systems in Israel encourage in different ways the involvement of the parents in institutionalized education. It was found that the parents' involvement contributes both to the students' social adjustment and to their scholastic achievements. ${ }^{28} \mathrm{~A}$ main part of parental involvement (of any type) is the existence of a system of reciprocal communication between parents and teachers, two-way communication with the goal of creating a system of relations based on trust, providing information on the curriculum and its goals, providing information on problems at home, holding a discussion, changing opinions, increasing the access of the teachers to the parents requests, and receiving updates on the situation of the students' studies.

The parents' involvement occurs in the best way when there is ongoing and effective communication between them and the teachers. ${ }^{29}$ In recent years, with the extension of the use of new technologies of communication and information, the use of these channels of communication between the parents and the teachers has increased.

The concept of 'new communication technologies' refers to communication such as computers or smartphones, which are based on the Internet. In the context of Internet-supported communication channels, we discuss the use of a school communication system supported by the school website (such as Mashov), email and social networks, technologies supported by mobile phones that primarily address messaging (SMS) and WhatsApp messages. Since the new communication channels enable the direct transfer of messages, without the mediation of the students, at any time and at any place, the use increases significantly the mutual availability existing between the parents and the teacher.

This chapter focuses on the characteristics of communication between parents and teachers in the era of an information society and the types of communication that exist today in the schools. The main goal is to present a number of conclusions regarding the adjustment of every channel to the different types of relationship between teachers and parents. The fundamental assumption is that communication between parents and teachers is a process of the exchange of information, formation of conventions, involvement in the educational processes, coordination of actions, fulfilment

28 R.B. Neal, Checking in or checking out? Investigating the parent involvement reactive hypothesis, The Journal of Educational Research, 2012, 105, p. 79-89.

${ }^{29}$ K.V. Hoover-Dempsey, M.C. Whitaker, C.L. Ice, Motivation and commitment to familyschool partnerships, [in:] Handbook of school-family partnerships, Eds. S.L. Christenson, A.L. Reschly, New York 2010, p. 30-60. 
of needs of the different sides, and effective emphasis of educational goals. The literature notes that to create effective communication between teachers and parents, the teachers' initiative is important. They must create a high frequency of contact with the parents and encourage the parents to be involved both in the school activity and in their children's learning process. 30

In this sense, the communication between teachers and parents needs to be positive and supportive, so that it can create opportunities for cooperation and for the encouragement of the continuation of the mutual communication. It is important to state that despite the feeling that exists in the public, according to which access to the Internet and use of smartphones are universal, the data indicate significant differences between different groups in the population, both in accessibility to the Internet and in the use of smart devices. The knowledge about these gaps is important, since it defines the target population that can benefit from this communication as opposed to a population that can benefit only from face-to-face communication or communication by regular means (letters or class notebook).

Digital Gaps. In the discussion of technology-supported communication, it is necessary to take into account that in Israel there are 'digital gaps'. A first order digital gap is the difference between the ability of groups in society to use information and communication technologies such as the Internet and smartphones. A second order digital gap is the gaps that exist in the computer use skills between groups that have the possibility of using these technologies. Regarding digital gaps of the first order, in Israel the data are relatively current. It becomes clear that $80 \%$ of households in Israel have a home computer but only $71 \%$ have an Internet connection. In the division by the decile according to average net income per person, there are large gaps in ownership of a computer and Internet connection: $95.5 \%$ of the households in the top decile have a computer in comparison to only $60 \%$ of households in the bottom decile, while $93.2 \%$ of the households in the top decile have an Internet subscription as opposed to only $38.1 \%$ in the bottom decile. ${ }^{31}$

A clear conclusion that derives from the data presented in the previous paragraph is that the use of new technology channels in the school obligates the examination in every class and in every school of the level of accessibility of these means to parents and the degree of use of computers and smart-

${ }^{30} \mathrm{~L}$. Ho, C. Hung, H. Chen, Using theoretical models to examine the acceptance behavior of mobile phone messaging to enhance parent teacher interactions, Computers \& Education, 2013, 61, p. 105-114.

31 Central Bureau of Statistics, Findings from a Survey of Household Expenses, 2012, 2013. 
phones. Especial attention is required in making intelligent decision on the level of the use of technology, so as to prevent a situation that the parents remain disconnected from this relationship with the teachers.

Technological availability. The research study differentiates between reliance on stationary technology (such as the home computer) and reliance on mobile technology (such as smartphones). The use of mobile devices significantly changes the frequency of the communication between parents and teachers. ${ }^{32}$ The possibility of carrying the device everywhere at all times causes the contacts of parents with teachers and teachers with parents to be held very frequently and at all hours of the day, even after the end of the studies in the school. It appears that the fundamental assumption of the contacts is that the very use of mobile devices dictates a norm of availability, which primarily obligates the teachers to be available for the parents at all times and places. This creates a load of communication and the blurring of the boundaries between the private life, both of the teachers and of the parents, and the educational obligations of the teachers and the reciprocal expectations of immediate availability. The accessibility and availability that develop may harm the effectiveness and efficiency of the communication and the teachers' ability to meet the parents' expectations. The teachers report overload and possible harm in their private lives because of the difficulty with setting a boundary between work and private life..$^{33}$

'Digital immigrants' and 'digital natives'. Aside from the gaps that exist in the accessibility and availability of technology between groups in the population, there is a significant intergenerational gap in the attitude of parents and adolescents to technology. The name 'digital natives' is the name given to the generation of people born in the middle of the 1980s and later, who grew up in a world of information and digital communication. The name 'digital immigrants' is the name given to the generation born before the year 1964, who grew up in a world before the personal computer. ${ }^{34}$ The practical meaning is the perception that 'digital natives' live the language and culture of the Internet, alongside which they grew up. The terms express essential differences between the generations in the understanding and use of technology, with the recognition that beyond the regular generation gap there are also many other differences between the generations, both in the technological ability and in the interest and desire to understand and use the technology.

${ }^{32}$ G. Kortz, Uses of new media: Collection of data from interested parties - Teachers and parents: A review of the literature, National Academy of Sciences, 2014.

33 Ibidem.

${ }^{34}$ M. Prensky, Digital natives, digital immigrants, On the Horizon, 2001, 9. 
This generational gap in relation to the technology is perceived as influencing the adolescent's system of relations with his parents and with his teachers. The main argument on the matter of the intergenerational differentiation is that the generation of 'digital natives' addresses learning in a manner different from the previous generation. They are accustomed to learn through the simultaneous use of many channels of information (such as photographs, films, and digital information search using a search engine) and can hold social relations through the simultaneous use of a large number of channels. This may constitute a focus of conflict between teachers and students and between parents and adolescents. ${ }^{35}$ In addition, parents find it difficult to achieve mastery of the channels of communication that the youths prefer and therefore problems in communication frequently arise between parents and children. The reason is that the communication of youths is based primarily on sparse channels of communication and on the young people's use of the language of abbreviations typical of their peer group, a language that frequently is not understood by their parents. ${ }^{36} \mathrm{In}$ contrast to the parents and the teachers, the youths are less troubled by the need to maintain privacy, a situation that weakens the borders of privacy, both of the school and of the family. Moreover, in the scholastic realm the children frequently prepare homework during conversations on new channels of communication with peers, while watching clips and writing on Twitter. These facts awaken concerns in the parents about their children's ability to focus on the scholastic tasks and the feeling that the children are becoming addicted to technology. It is possible that the intergenerational gap will disappear over time, but at this stage the awareness of it is very important to the understanding of the communication between parents and children. Hence, this understanding is also important to the understanding of the implications of the new means of communication on the beneficial relations between parents and teachers.

\section{Students and Their Parents' Involvement}

Trager ${ }^{37}$ emphasized that the parents' behavior largely determines their child's level of achievement, the place of his self-control, the level of his cu-

\footnotetext{
${ }^{35}$ L.M. Padilla-Walker, S.M. Coyne, A.M. Fraser, Getting a high-speed family connection: Associations between family media use and family connection, Family Relations, 2012, 61, p. 426-440.

${ }^{36}$ L. Rosen, Rewired: Understanding the iGeneration and the way they learn, Palgrave Macmillan, New York 2010.

${ }^{37} \mathrm{H}$. Trager, There is no education without parents, parental involvement drives achievements, Between the Bells, A Collection. Studies in Education, Technology, and Science, 2012, March 12, Ort Israel.
} 
riosity, and his self-image. She cited the Rotli Committee, which submitted in the year 2003 its report, which defines the parental responsibility necessary in Israeli law and what the State needs to perform to fill this responsibility. In addition, Trager noted that if the child is the eldest child in the family, then the parents will display greater involvement than with a second or third child in the family.

Thorne ${ }^{38}$ researched the influence of the parents' involvement on adolescents. The social context of the school students is multi-system. The immediate environment includes a number of systems in which the family and the school have a significant and important part. The family and school processes have a decisive impact on the children's functioning - there is no argument about this. The question that is asked in this context is as follows. What is the pattern of the parents' involvement that contributes to the adolescents' development? The research findings indicate that the parent's involvement in the school has an influence on the adolescent's scholastic achievements and self-esteem.

A research study performed by Greenwald ${ }^{39}$ in four elementary schools examined the relation between the parents' involvement and the atmosphere and culture in the school as well as the quality of the teaching and the education. The research study found that as the parents are more involved in the school, a more open climate is created. In addition, the research study found a relationship between the school type, the students' socioeconomic level, and the parents' degree of involvement. The researcher used the research findings to propose a model that may help the classes' homeroom teachers incorporate the parents in the activity.

Fisher and Friedman ${ }^{40}$ also noted the findings that a prominent positive relationship was found between the parents' involvement and their children's achievements. However, some students see themselves as 'big' and are concerned that their parents' involvement will harm them more than help them, since according to the students' perceptions the teachers see the parents to be an intervening and undesired factor and therefore they - the students - may pay the price.

38 N. Kaplan Thorne, Parent involvement, self-esteem, and student achievements in the middle school, Ph.D. Dissertation, Haifa University 2004.

${ }^{39}$ E. Greenwald, Parents' involvement in the elementary school and influence on climate, culture, and education, Oranim College, 2007.

${ }^{40}$ Y. Fisher, Y. Friedman, Parents and the school-Reciprocal relations, p. 11-37. 


\section{Survey Population}

Youths in the seventh to ninth grades who are learning in a school in the north of Israel participated in the survey. A total of 33 participants were selected, $48 \%$ male and $52 \%$ female. The participants are divided by age as follows: $33 \%$ seventh grade, $45 \%$ eighth grade, and $21 \%$ ninth grade. The youths who were selected to answer the questionnaires are socially active both in the school and in community activity after the school hours. The number of respondents is relatively low, but it enables us to obtain a sense of direction on the attitudes of the youths regarding their parents' involvement in the school.

In the survey the students were asked to note the number of people at home, their position in the family, their scholastic situation, and the degree of their parents' involvement in the school. In addition, the students' attitudes towards their parents' areas of involvement in the school were examined, as well as the extent to which the students are interested in taking part in shared activity of parents, teachers, and students. These attitudes were examined in addition to the level of the student's social involvement in his class.

\section{Survey Conclusions}

In the examination of the questionnaires, it is possible to identify that the youths' response to projects such as roots and Bar-Mitzvah is great, about $50-60 \%$. This can be attributed to the fact that the youths come from traditional families. In other areas, the students do not see a place for joint activity with them and their parents. It is likely that some are afraid about harm to their social status in such joint activity.

The questionnaires show that as the students' are older, their objection to the parents' involvement increases. This finding reinforces research studies conducted in elementary schools, where it was found that the level of objection to the parents' involvement increases with the students' increase in age.

The survey shows that $50 \%$ of the respondents are children of older parents. Namely, they are the third child in the family, according to the average of five people in the family in this survey. When we examine the level of the parents' involvement in the school according to the students' reports, we learn that in recent months $75 \%$ of the parents were not in contact with the 
school at all. This datum reinforces the article of Trager ${ }^{41}$, who noted that the parental involvement level declines as the number of children in the family increases.

In most fields of parental involvement, more than $50 \%$ of the students are not interested in their parents' involvement at all. The areas in which there is more interest for students regarding the parental involvement is class activities, as opposed to school activities. However, it is possible to identify among the students in all areas of parental involvement a type of avoidance/indifference to the point of lack of caring regarding the involvement of their parents in the school. It is possible that this must be examined among the parents. The lack of parental involvement, as expressed in the questionnaire, strengthens the impression that the problem lies with the parents and not with the students' attitude. This strengthens with the fact that $75 \%$ of the parents were not involved at all in the past two months, $15 \%$ were involved only once in the past two months, and 9\% were involved only twice in the past two months.

The mean of the school scores of all the respondents in this survey is defined by them as good to very good. This datum contradicts the research studies, which found a relationship between the parents' involvement and success in the studies ${ }^{42}$.

The research study shows that many of the parents and the teachers use advanced technological means (email, Skype, WhatsApp). This reality can constitute an explanation of the parents' lack of physical presence in the school. Perhaps this explains the fact that $75 \%$ of the parents do not take part in school activity at all.

\section{Summary}

Much has been said about the parents' involvement in the school. In many of the cases, students are talked about and not talked with. This article attempted to focus on the students, with focused reference to the age of the middle school. This age is defined as adolescence, and hence the tension and influences of age also impact the school. At this age, the peer group has critical impact on the youths, their behavior, and their approach. One of the most common dilemmas in adolescence is the degree of freedom that should be given to adolescents. The issue of setting boundaries is one of the main

\footnotetext{
${ }^{41} \mathrm{H}$. Trager, There is no education without parents.

42 Y. Fisher, Y. Friedman, Parents and the school - Reciprocal relations, p. 11-37.
} 
ones in adolescence, and frequently it creates conflicts between parents and adolescents. In essence, the need to set boundaries creates a dilemma, which causes confusion and tension among both parents and adolescents. If in the past (before the era of the Internet and the smartphone), the relationship between the teachers and the parents was based on phone contact, a contact notebook, and invitations to the school, in our era, with the technological development, new patterns of communication and parental involvement have been created. This article presented a variety of these modes of communication. I have no doubt that the immediate contact through the smartphone and the parents' ability to follow-up and communicate through the school website have created a new situation in which the parental involvement is not always physical and sometimes, although it is virtual, it is considered involvement and good and immediate contact. Reinforcement of this perception is obtained from the survey, in which students who define themselves as good to very good students and are socially involved in their class note that only $25 \%$ of the parents participated in school activity.

\section{Acknowledgments}

I would like to thank the Faculty of Educational Sciences at Adam Mickiewicz University in Poznan for providing me with the physical conditions such as access to articles and use of bibliography and for the supportive guidance of Professor Pyżalski, who helped me greatly in the work on this article.

\section{BIBLIOGRAPHY}

Addi-Raccah A., Ainhoren R., School governance and teachers' attitudes to parents involvement in schools, Teaching and Teacher Education, 2009, 25(6).

Bauch P.A., Goldring E.B., Parent-teacher participation in the context of school governance, Peabody Journal of Education, 2000, 73(1).

Binns Y., The use of the Mashov [Immediacy, Transparency, Supervision] program in the dialogue between the parents and the school: The Kafr Kaana middle school, M.A. Thesis, The Open University 2008 (Hebrew).

Blau A., Hameiri M., Smartphone in the school - Is the next generation really here? Pedagogical management of the mobile phone in the educational staff and in the families, [in:] The learning person the technological era, Eds. Y. Ashet Alkaly, A. Kaspi, N. Gary, Y. Kellman, V. Silver-Varod, Y. Yair, 2011 (Hebrew).

Blau A., Hameiri M., A new way to realize the right to know: Increase of the involvement of students and parents in what is done in the educational institutions through an online system for pedagogical management - Mashov [Immediacy, Transparency, Supervision], http://goog.gl/BO1pxt, 2012 (Hebrew). 
Brooks S., Boskilla D., Incorporation of Facebook as a means of communication between teachers and parents: Action research, M.A. Thesis, The Center for Academic Studies 2013 (Hebrew).

Central Burea of Starsitics, Findings from the Household Expenses Survey 2012: Retrieved on July 27, 2014 from: www.cbs.gov.il/www/hodaot2013n/15_13_343b.doc (Hebrew).

Erikson E.H., Childhood and society, HaPoalim Press, Tel Aviv 1983 (Hebrew).

Fisher Y., Friedman Y., Parents and the school - Reciprocal relations and involvement, Pages, 2002, 47, 11-37 (Hebrew).

Fisher Y., Friedman Y., Parents and the school: Reciprocal Relations and involvement, Research instruments series, Szold Institute, Jerusalem 2009 (Hebrew).

Friedman Y., Relations between school and parents in Israel: background material for the work, 2010 (Hebrew).

Greenbaum Z., Fried D., Family relations in the framework of early childhood education: Picture of the Situation and recommendations, Israel National Academy for Sciences 2008 (Hebrew).

Greenwald E., Parents' involvement in the elementary school and influence on climate, culture, and education, Oranim College 2007 (Hebrew).

Ho L., Hung C., Chen H., Using theoretical models to examine the acceptance behavior of mobile phone messaging to enhance parent teacher interactions, Computers \& Education, 2013, 61.

Hoover-Dempsey K.V., Whitaker M.C., Ice C.L., Motivation and commitment to familyschool partnerships, [in:] Handbook of school-family partnerships, Eds. S.L. Christenson, A.L. Reschly, Routledge, New York 2010.

Kaplan Thorne N., Parent involvement, self-esteem, and student achievements in the middle school, Ph.D. Dissertation, Faculty of Education, Haifa University 2004 (Hebrew).

Kortz G., Uses of new media: Collection of data from interested parties - Teachers and parents: A review of the literature, National Academy of Sciences 2014 (Hebrew).

Kortz G., Chen D., Intentional online learning - A digital toolkit for the teacher, Center for Academic Studies, Or Yehuda 2012 (Hebrew).

Kosaretskii S.G., Chernyshova D., Electronic communication between the school and the home, Russian Education and Society, 2013, 55(10).

Meeus W., Parental and peer support in adolescence, [in:] The social world of adolescents, Eds. K. Hurrelmann, U. Engel, American Educational Research Association, New York 1989.

Meizles E., Relations between parents and adolescents with the transition to adolescence, Trends, 2001, 41(1-2) (Hebrew).

Ministry of Education Adjustment of the educational system to the 21st century: Masterplan, 12th edition, 2012, http://goog.gl/6oKIJb (Hebrew).

Mitchell S.A., Black M.G., Freud and transition, Tolaat Sefarim, Tel Aviv 2006 (Hebrew).

Mor A., To speak with the parents even when 'everything is alright', Echo of Education, 2012, 90 (Hebrew).

Neal R.B., Checking in or checking out? Investigating the parent involvement reactive hypothesis, The Journal of Educational Research, 2012, 105.

Olmstead C., Using technology to increase parent involvement in schools, TechTrends, 2013, $57(6)$.

Padilla-Walker L.M., Coyne S.M., Fraser A.M., Getting a high-speed family connection: Associations between family media use and family connection, Family Relations, 2012, 61. 
Perlman M., What are the reciprocal relations between the teachers' use of systems for information management and their sense of accountability? [in:] The learning person the technological era, Eds. Y. Ashet Alkaly, A. Kaspi, N. Gary, Y. Kellman, V. Silver-Varod, Y. Yair, 2014 (Hebrew).

Piaget J., The psychology of the child (transl. Y. Sternberg), Tel Aviv 1972 (Hebrew).

Plotkin A., Shapira T., Contribution of the cooperation between the school and the parents in the construction of educational authority, Trends in the Administration of Education 2013 Conference, Book of Abstracts, Gordon Academic College 2013 (Hebrew).

Prensky M., Digital natives, digital immigrants, On the Horizon, 2001, 9.

Rosen L., Rewired: Understanding the iGeneration and the way they learn, Palgrave Macmillan, New York 2010.

Rotenberg K.J., The socialisation of trust: parents' and children's interpersonal trust, International Journal of Behavioral Development, 1995, 18.

Salomon G., Technology and education in the information era, Haifa University and Zmora Beitan, Haifa and Tel Aviv 2000 (Hebrew).

Sohlberg S., Psychology of the child and the adolescent - Introduction to developmental psychology, The Hebrew University of Jerusalem, Magnes Press, Jerusalem 1994 (Hebrew).

Statman D., Moral dilemmas, The Hebrew University of Jerusalem, Magnes Press, Jerusalem 1991 (Hebrew).

Thompson B., Characteristics of parent-teacher e-mail communication, Communication Education, 2008, 57(2).

Thompson B., Parent-teacher e-mail strategies at the elementary and secondary school, Qualitative Research Reports in Communication, 2009, 10(1).

Trager H., There is no education without parents, parental involvement drives achievements, Between the Bells, A Collection. Studies in Education, Technology, and Science, 2012, March 12, Ort Israel (Hebrew). 